\title{
Article \\ Catalytic, Regioselective Sulfonylation of Carbohydrates with Dibutyltin Oxide under Solvent-Free Conditions
}

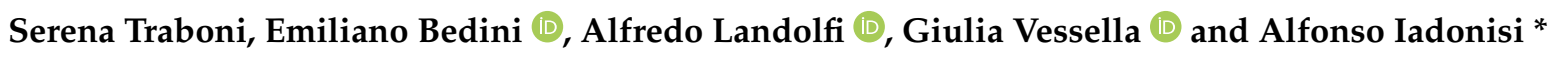 \\ Department of Chemical Sciences, University of Naples Federico II, Via Cinthia 4, I-80126 Naples, Italy; \\ serena.traboni@unina.it (S.T.); ebedini@unina.it (E.B.); alfredo.landolfi@gmail.com (A.L.); \\ giulia.vessella@unina.it (G.V.) \\ * Correspondence: iadonisi@unina.it
}

check for

updates

Citation: Traboni, S.; Bedini, E.;

Landolfi, A.; Vessella, G.; Iadonisi, A. Catalytic, Regioselective

Sulfonylation of Carbohydrates with Dibutyltin Oxide under Solvent-Free Conditions. Catalysts 2021, 11, 202. https://doi.org/10.3390/catal11020202

Academic Editor: Helmut G. Alt

Received: 31 December 2020

Accepted: 1 February 2021

Published: 3 February 2021

Publisher's Note: MDPI stays neutral with regard to jurisdictional claims in published maps and institutional affiliations.

Copyright: (c) 2021 by the authors. Licensee MDPI, Basel, Switzerland. This article is an open access article distributed under the terms and conditions of the Creative Commons Attribution (CC BY) license (https:/ / creativecommons.org/licenses/by/ $4.0 /)$.

\begin{abstract}
A simple approach was developed for the solvent-free regioselective functionalization of carbohydrate polyols with 4-toluesulfonyl (tosyl) group, allowing the easy and quick activation of a saccharide site with a tosylate leaving group. The method is based on the use of catalytic dibutyltin oxide and tetrabuylammonium bromide (TBAB), and a moderate excess of $N, N$-diisopropylethyl amine (DIPEA) and tosyl chloride ( $\mathrm{TsCl}$ ), leading to the selective functionalization at $75{ }^{\circ} \mathrm{C}$ of a secondary equatorial hydroxy function flanked by an axial one in a pyranoside. The procedure is endowed with several advantages, such as the use of cheap reagents, experimental simplicity, and the need for reduced reaction times in comparison with other known approaches.
\end{abstract}

Keywords: solvent-free reaction; regioselectivity; tosylation; tin catalysis; carbohydrates; polyols; leaving group

\section{Introduction}

Carbohydrates are well-appreciated precursors in organic synthesis owing to both their broad availability at a low cost and their dense functionalization with a large number of defined stereo-centers. They are typically elaborated to different saccharides (rare monosaccharides, oligosaccharides), glycomimetics, or non-saccharide chiral compounds [1]. All these applications unavoidably entail reactivity discrimination for the numerous functional groups present in each saccharide residue, and protecting group chemistry plays a pivotal role to this end. However, the selective modification of carbohydrates can also entail substitution or elimination reactions, whereby well-defined saccharide positions are activated with the installation of leaving groups. In this frame, the 4-toluenesulfonyl (tosyl) group represents a cheap option adopted for both primary and secondary saccharide positions [2-19]. The development of streamlined entries to carbohydrates selectively tosylated at secondary positions has been underway for a long time, and initial attempts were based on the use of stoichiometric dibutyltin oxide to regulate the site selectivity through the preliminary generation of cyclic stannylene acetals [20]. Many years later, protocols with catalytic dibutyltin oxide were developed [21-23], allowing, similarly to the preceding stoichiometric version, the selective functionalization of equatorially oriented secondary alcohols adjacent to axial ones. This selectivity arises from a halide-induced opening of the stannylene acetal, via an anionic complex, which favors the selective functionalization of the more accessible equatorial oxygen. Tetrabutyl ammonium halides are typically adopted as a source of halides to trigger such a mechanism. This methodology was further refined by adopting catalytic dimethyltin dichloride, and a very thorough analysis of the reaction parameters (arylsulfonating agent, additives, etc.) led to the selection of the 3,5-(trifluomethyl)arylsulfonyl group as an alternative to tosyl, this latter being introduced at a much lower yield under the disclosed optimized conditions [24]. Unlike most catalytic approaches herein recalled (see also below), this methodology proved compatible with the selective functionalization of secondary alcohols in the presence of 
primary ones, but suffered from both the use of an arylsulfonating reagent much more expensive than tosyl chloride, and the need for prolonged reaction times. In the search for alternative catalytic systems, a set of boron-based catalysts was successfully developed to conduct the regioselective derivatization of saccharides, including tosylation reactions, which proceeded with a regioselective control analogous to that of the tin-based methodologies. In 2012, borinic acids proved useful to this end, with reactions working at room temperature in $48 \mathrm{~h}$ on substrates preliminarily protected at primary positions [25]. In 2019, chiral benzazaboroles were shown to be effective catalysts at room temperature, even in the presence of primary alcohols, with reactions taking prolonged times (about $20 \mathrm{~h}$ ) to occur [26]. In 2020, benzoxaborole was described as an alternative catalyst working in $24 \mathrm{~h}$ at RT with substrates protected at primary positions [27]. In the same year, a catalytic iron complex generated in situ from $\mathrm{FeCl}_{3}$ and benzoyltrifluoroacetone was proposed as a catalytic system working at RT (several hours), once again with substrates protected at primary positions [28].

Over the last few years, there has been a growing interest in the development of solvent-free approaches focused on synthetic carbohydrate chemistry [29], and numerous contributions were provided by our laboratory, with the proposal of non-conventional and experimentally simple procedures for the regioselective protection of sugars with benzyl [30-33], allyl [31], silyl [34,35], trityl [35,36] and acetal groups [37], and the possible sequential application thereof in one-pot procedures $[34,36,38]$. In this frame, the mentioned benzylation/allylation procedure [31] represented the first example at the use of catalytic dibuyltin oxide for stannylene-mediated alkylations, after about 30 years of stoichiometric applications. Solvent-free approaches were also developed to address one of the key issues in oligosaccharide synthesis, namely, the glycosidation reaction [39-42]. Further, two alternative solvent-free methods were also developed to introduce leaving groups at well-defined saccharide positions, leading to either the anomeric chlorination [43] or the regioselective iodination of primary positions [44]. The study herein described is aimed at further extending the synthetic scope of solvent-free methodologies with the regioselective installation of a tosylate leaving group at the secondary positions of sugars.

\section{Results}

Initial experiments were designed to test the feasible applicability of solvent-free conditions in order to achieve fast regioselective tosylation at the secondary site of sugar polyols with a free primary function. For this purpose, commercial methyl mannoside 1 was initially selected as the model compound. The selection of initial stoichiometric conditions was inspired by the previously optimized benzylation procedure [31], with the use of catalytic dibutyltin oxide ( 0.1 equiv.) and tetrabutylammonium bromide (TBAB) ( 0.3 equiv.). The optimization conducted on the benzylation procedure also evidenced that the liquid diisopropylethyl amine (DIPEA) is by far the best base for these solvent-free reactions, and a stoichiometric excess of 3-4 equivalents, although unable to dissolve the reagents, was sufficient to achieve high-yielding reactions.

First, tosylation experiments were aimed at finding the optimized temperature conditions, and $75{ }^{\circ} \mathrm{C}$ proved to be the best compromise for achieving both fast reactions and satisfying yields. Actually, at lower temperatures, the reaction was sluggish (data not shown), whereas at higher temperatures the yield was eroded by the generation of high amounts of di-O-tosylated side-products (Table 1, entry 1 ). This composition of the crude reaction mixture evidenced that the tosylation of $\mathbf{1}$ (to yield $\mathbf{3}$ ) and the further tosylation of 3 (mainly at O-6) proceeded at a comparable rate. In an attempt to maximize the yield of $\mathbf{3}$, the effect of the stoichiometric amount of DIPEA and tosyl chloride was examined. In the presence of a minimal excess of tosyl chloride (1.2 equiv.) (Table 1, entry 2), a prevalent recovery of starting polyol was observed, whereas with 2 equiv. the desired product 3 was mainly accompanied by di- $O$-tosylation products (Table 1 , entry 5 ). A moderate excess of tosyl chloride (1.5 equiv.) provided compound 3 in a yield similar to when using 2 equiv., but the conversion was noticeably higher, owing to the possibility of recovering unreacted 
1 (Table 1, entry 4). The use of a lower DIPEA excess (3 equiv. rather than 4) (Table 1, entry 3) resulted in a slight decrease in the yields. The optimized conditions in entry 4 proved applicable also to the regioselective 3-O-tosylation of galactoside 2 , affording 4 in a very satisfying yield (Table 1, entry 6). As with other solvent-free modifications of carbohydrates previously described, the initial heterogenous mixture of solid and liquid reagents gradually turned into a homogeneous slurry.

Table 1. Regioselective tosylation of saccharide tetrols.

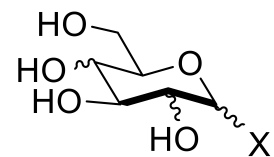

1 Man X: $\alpha$-OMe

2 Gal $X: \beta-S E t$

$$
\begin{aligned}
& \mathrm{Bu}_{2} \mathrm{SnO}(0.1 \text { equiv). } \\
& \mathrm{Bu}_{4} \mathrm{NBr}(0.3 \text { equiv), } \\
& \mathrm{DIPEA}(4 \text { equiv), } \\
& \underset{\mathrm{TsCl} \text { (x equiv) }}{\stackrel{\text { Temp, } 1.5-3 \mathrm{~h}}{\longrightarrow}}
\end{aligned}
$$

\begin{tabular}{|c|c|c|c|c|}
\hline Entry & Polyol Sugar & Equiv. TsCl & Temperature & Product and Yield \\
\hline \multirow[t]{2}{*}{1} & -10 & 1.5 & $85^{\circ} \mathrm{C}$ & $\underset{\mathrm{HsO}-}{\mathrm{HO}-}$ \\
\hline & 1 & & & $328 \%$ b \\
\hline 2 & 1 & 1.2 & $75^{\circ} \mathrm{C}$ & $336 \%$ \\
\hline $3^{a}$ & 1 & 1.5 & $75^{\circ} \mathrm{C}$ & $341 \%$ \\
\hline 4 & 1 & 1.5 & $75^{\circ} \mathrm{C}$ & $346 \%{ }^{c}$ \\
\hline 5 & 1 & 2.0 & $75^{\circ} \mathrm{C}$ & $342 \% b$ \\
\hline 6 & & 1.5 & $75^{\circ} \mathrm{C}$ & $\mathrm{TsO}-$ \\
\hline & 2 & & & $462 \%$ \\
\hline
\end{tabular}

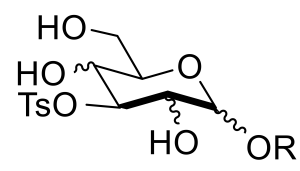

3 Man X: $\alpha$-OMe 4 GalX: $\beta$-SEt

Ts: $p-\mathrm{MeAr}-\mathrm{SO}_{2-}$

a 3 equiv. DIPEA (diisopropylethyl amine) was used; ${ }^{b}$ Prevalent recovery of poly-O-tosylated side products, c $34 \%$ recovery of the starting material.

This first set of experiments evidenced that, unlike most described methods, the tincatalyzed solvent-free tosylation of sugars can be compatible with free primary alcohols, affording synthetically useful yields in relatively short reaction times, not exceeding three hours. An accurate control of the temperature was found to be critical to achieve good yields in short reaction times.

The availability of simple solvent-free methods for the quick and high-yielding 6-Oprotection of sugars with silyl [34] and trityl groups [36] spurred us to explore the reactivity of sugar building-blocks protected at primary positions with such groups (Table 2, entries 1-5). With these less polar substrates, a lower DIPEA excess (3 equiv.) was generally effective to conduct the tin-catalyzed tosylations, and excellent yields were achieved in short reaction times (Table 2, entries 1-3) with substrates 5-7 protected with either the tertbutyldimetylsilyl (TBS) or the tert-butyldiphenylsilyl (TBDPS) group. A notably lower yield was instead noted with the 6-O-tritylated manno-substrate 8 (trityl: $\mathrm{Tr}$ ), which provided the desired compound 16 in ca 50\% (Table 2, entry 4), accompanied by the corresponding triol derivative deprotected at $0-6$. This undesired de-O-tritylation was suppressed by conducting the reaction in the presence of a slightly larger excess of DIPEA (4 equivalents in place of 3), and a remarkable increase in yield was consequently achieved (Table 2, entry 5). 
Table 2. Regioselective tosylations of sugars protected at primary positions.

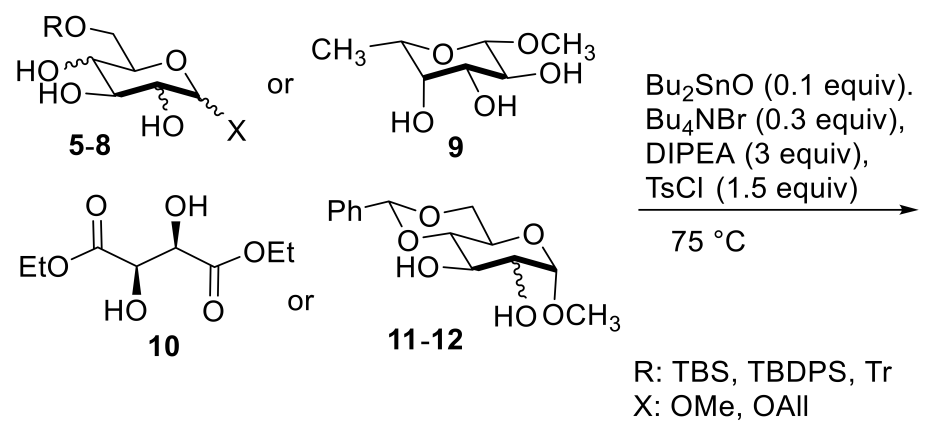

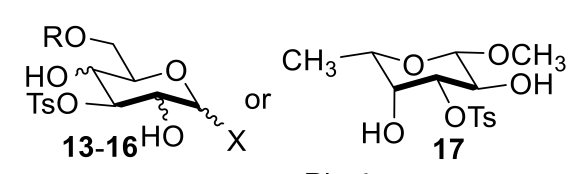

$\underbrace{O H O}_{18}$

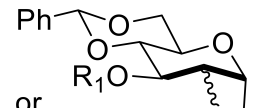

19-20 $\mathrm{R}_{2} \mathrm{OOCH}_{3}$

$\mathrm{R}_{1}$ : $\mathrm{H}$, Ts

$\mathrm{R}_{2}$ : Ts, $\mathrm{H}$

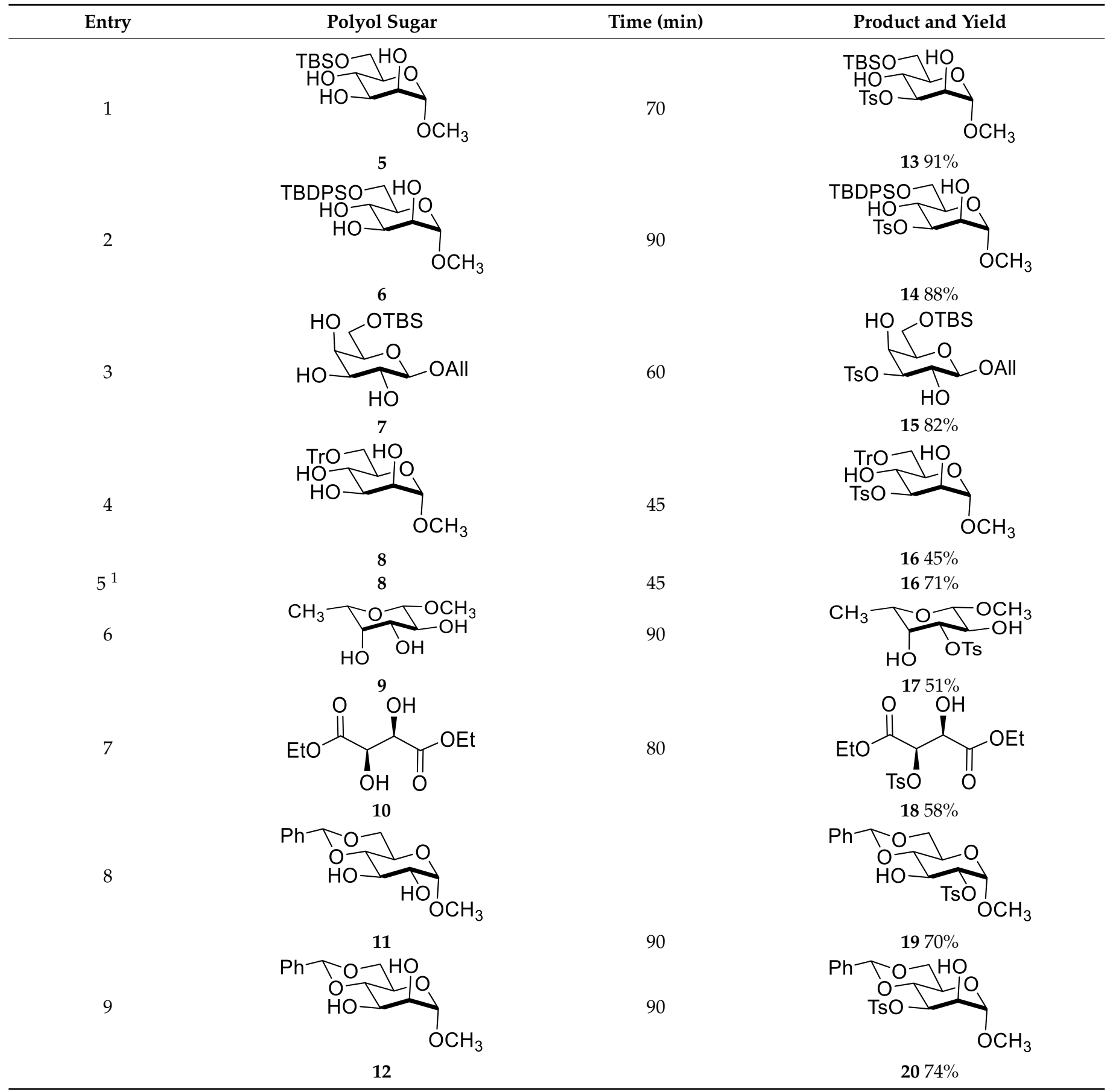

\footnotetext{
${ }^{1} 4$ equiv. DIPEA were used.
} 
The scope of the approach was then assessed with other polyols of a saccharide and non-saccharide nature (Table 2, entries 6-9). A satisfying result was recorded with $\beta$-fucoside 10 (Table 2, entry 6), which provided the expected 3-O-tosylated derivative. The non-saccharide tartrate 11 (Table 2, entry 7), bearing two equivalent alcohol functions, was selected to test the chemoselectivity induced by the tin catalyst, expected to favor the mono-O-tosylation product $\mathbf{1 8}$. As a matter of fact, $\mathbf{1 8}$ was obtained as the predominant product in a yield similar to that reported in the solution approach [22]. The method also gave good yields with gluco- and manno-building blocks 11 and 12, equipped with an acid-sensitive benzylidene protecting group (Table 2, entries 8 and 9, respectively). In both cases, an elevated regioselectivity was observed, and this achievement was especially remarkable in the case of the gluco-substrate $\mathbf{1 1}$ (Table 2, entry 8) bearing a diequatorial trans-diol. Although the preferential 2-O-tosylation was also described for $\mathbf{1 1}$ with a protocol based on a stoichiometric tin activation [45], this result was interesting for this catalytic approach, having previously observed that the solvent-free benzylation conducted on 11 under similar stoichiometric conditions (catalytic $\mathrm{Bu}_{2} \mathrm{SnO}, \mathrm{TBAB}$ and DIPEA excess) afforded comparable amounts of mono-O-benzylation products at $\mathrm{O}-2$ and $\mathrm{O}-3$, and the reaction was also much slower than with the corresponding manno-analogue 12 (expectedly benzylated only at equatorial $O$-3) [31]. In contrast, as evidenced in the comparison of entries 8 and 9 , the tosylation of $\mathbf{1 1}$ and $\mathbf{1 2}$ proceeded at a very similar rate, as well as with high regioselectivity. The different behavior of 4-toluenesulfonyl chloride and benzyl bromide towards diequatorial diol $\mathbf{1 1}$ under tin-catalysis emphasizes that the specific nature of the electrophilic agent plays a critical role in determining the reactivity and the selectivity of the stannylene acetal intermediates generated from a trans-diol. This effect seems consistent with results reported in a study by Dong and coworkers [46], concerning the tin-catalyzed functionalization of trans-diols, whose regioselectivity was shown to be critically dependent on the specific nature of the alkylating agent. Collectively, it is worth pointing out that all the reactions described in Table 2 took very short times, never exceeding $90 \mathrm{~min}$.

\section{Materials and Methods}

\subsection{General Remarks}

All chemicals adopted (diisopropylethyl amine, para-toluensulfonyl chloride, dibutyltin oxide, tetrabutylammonium bromide) were commercially available and used without further purification. NMR analysis was performed on a Bruker $400 \mathrm{MHz}$. The progress of reactions was monitored by TLC; after elution in the suitable eluent, the plates were soaked in $5 \%$ concentrated $\mathrm{H}_{2} \mathrm{SO}_{4}$ in ethanol and heated at $230{ }^{\circ} \mathrm{C}$. All reactions were performed in air.

\subsection{General Procedure of Regioselective Tosylation}

The saccharide substrate $(0.5 \mathrm{mmol})$, dibutyltin oxide $(12 \mathrm{mg}, 0.05 \mathrm{mmol})$, TBAB ( $48 \mathrm{mg}, 0.15 \mathrm{mmol}$ ) were weighted and ground in a $5-10 \mathrm{~mL}$ glass vessel. DIPEA (3-4 equiv.) was added dropwise to the of solids and the mixture was allowed to stir in a fume hood at $75^{\circ} \mathrm{C}$ for five minutes, then toluensulfonyl chloride (1.2-1.5 equiv.) was added. The mixture was kept under stirring until TLC analysis displayed an optimal conversion (see Tables 1 and 2 for reaction times). The resulting crude material was concentrated under vacuum, and then transferred with multiple washings with dichloromethane to a balloon, where it was concentrated under vacuum in the presence of flash-chromatography silica gel. The resulting white solid was loaded on the top of a silica gel column, and eluted with ethyl acetate (for triol products) or hexane/ethyl acetate mixtures (for products of lower polarity). Pure chromatographed products were obtained (according to signals of NMR spectra (Supplementary Materials)) with the isolated yields reported in Tables 1 and 2. The yields were evaluated by determining the millimoles of the isolated product from the corresponding weight, computing the ratio of the product millimoles to reagent millimoles, and 
converting this into a percentage. The tosylation site was determined by the observation of the downfield shift induced at ${ }^{1} \mathrm{H}$ NMR for the corresponding $\mathrm{CH}-\mathrm{OTs}$ signal.

\subsection{Spectral Data of Synthesized Products}

Methyl 3-O-(4-toluenesulfonyl)- $\alpha$-D-mannopyranoside 3 [26]

Eluted from the column with ethyl acetate. Rf (ethyl acetate) $0.45 .{ }^{1} \mathrm{H}$ NMR $(400 \mathrm{MHz}$, $\left.\mathrm{CDCl}_{3}\right) \delta / \mathrm{ppm}: 7.85$ and $7.33(2 \times \mathrm{d}, 4 \mathrm{H}, J=8.0 \mathrm{~Hz}$, aromatic protons), 4.68 (bs, $1 \mathrm{H}, \mathrm{H}-1)$, $4.58(\mathrm{dd}, 1 \mathrm{H}, J=2.8$ and $9.2 \mathrm{~Hz}, \mathrm{H}-3), 4.16(\mathrm{t}, 1 \mathrm{H}, J=10.0 \mathrm{~Hz}, \mathrm{H}-4), 3.92(\mathrm{bd}, 1 \mathrm{H}, J=2.8 \mathrm{~Hz}$, $\mathrm{H}-2), 3.80-3.60(\mathrm{~m}, 5 \mathrm{H}, 3 \times \mathrm{OH}, \mathrm{H}-5$ and $\mathrm{H}-6 \mathrm{a}), 3.50(\mathrm{bd}, 1 \mathrm{H}, J=9.2 \mathrm{~Hz}, \mathrm{H}-6 \mathrm{~b}), 3.31(\mathrm{~s}$, $\left.3 \mathrm{H},-\mathrm{OCH}_{3}\right), 2.42\left(\mathrm{~s}, 3 \mathrm{H}\right.$, tosyl $\left.\mathrm{CH}_{3}\right) .{ }^{13} \mathrm{C} \mathrm{NMR}\left(100 \mathrm{MHz}, \mathrm{CDCl}_{3}\right) \delta / \mathrm{ppm}: 145.0,133.0$, 129.8 (x2), 128.0 (x2), 100.4, 82.7, 72.1, 69.4, 63.4, 54.9, 21.6. MALDI HRMS $m / z[\mathrm{M}+\mathrm{Na}]^{+}$ $\left(\mathrm{C}_{14} \mathrm{H}_{20} \mathrm{O}_{8} \mathrm{SNa}\right)$, Calculated: 371.0777; Found: 371.0765 .

Thioethyl 3-O-(4-toluenesulfonyl)- $\beta$-D-galactopyranoside 4

Eluted from the column with hexane/ethyl acetate (from 1:4 to 0:1). Rf (ethyl acetate) 0.75. ${ }^{1} \mathrm{H}$ NMR $\left(400 \mathrm{MHz}, \mathrm{CDCl}_{3}\right) \delta / \mathrm{ppm}: 7.85$ and $7.33(2 \times \mathrm{d}, 4 \mathrm{H}, J=8.0 \mathrm{~Hz}$, aromatic protons), $4.48(\mathrm{dd}, 1 \mathrm{H}, J=3.2$ and $10.0 \mathrm{~Hz}, \mathrm{H}-3), 4.32(\mathrm{~d}, 1 \mathrm{H}, J=10.0 \mathrm{~Hz}, \mathrm{H}-1), 4.28$ (bs, $1 \mathrm{H}, \mathrm{H}-4), 4.00-3.75\left(\mathrm{~m}, 3 \mathrm{H}, \mathrm{H}_{2}-6\right.$ and $\left.\mathrm{OH}\right), 3.58(\mathrm{t}, 1 \mathrm{H}, J=5.2 \mathrm{~Hz}, \mathrm{H}-5), 3.18(\mathrm{bs}, 1 \mathrm{H}, \mathrm{OH})$, $2.73\left(\mathrm{~m}, 2 \mathrm{H},-\mathrm{SCH}_{2}-\right), 2.50(\mathrm{bs}, 1 \mathrm{H}, \mathrm{OH}), 2.44\left(\mathrm{~s}, 3 \mathrm{H}\right.$, tosyl $\left.\mathrm{CH}_{3}\right), 1.26(\mathrm{t}, 3 \mathrm{H}, J=6.8 \mathrm{~Hz}$, thioethyl $\left.\mathrm{CH}_{3}\right) .{ }^{13} \mathrm{C}$ NMR $\left(100 \mathrm{MHz}, \mathrm{CDCl}_{3}\right) \delta / \mathrm{ppm}$ : 145.0, 133.0, 129.7 (x2), 127.9 (x2), 86.1, 83.9, 77.7, 68.6, 67.2, 61.9, 24.2, 21.6, 15.0. MALDI HRMS $m / z\left[\mathrm{M}+\mathrm{Na}^{+}\left(\mathrm{C}_{15} \mathrm{H}_{22} \mathrm{O}_{7} \mathrm{~S} 2 \mathrm{Na}\right)\right.$, Calculated: 401.0705; Found: 401.0713.

Methyl 3-O-(4-toluenesulfonyl)-6-O-tert-butyldimethylsilyl- $\alpha$-D-mannopyranoside $13[25,28]$

Eluted from the column with hexane/ethyl acetate (3:2). Rf (hexane/ethyl acetate 1:1) 0.80. ${ }^{1} \mathrm{H}$ NMR $\left(400 \mathrm{MHz}, \mathrm{CDCl}_{3}\right) \delta / \mathrm{ppm}: 7.85$ and $7.33(2 \times \mathrm{d}, 4 \mathrm{H}, J=8.0 \mathrm{~Hz}$, aromatic protons), 4.69 (dd, $1 \mathrm{H}, J=2.8$ and $9.2 \mathrm{~Hz}, \mathrm{H}-3), 4.67$ (bs, $1 \mathrm{H}, \mathrm{H}-1), 4.00-3.85(\mathrm{~m}, 4 \mathrm{H}, \mathrm{H}-2$, $\mathrm{H}-4, \mathrm{H}-5$ and H-6a), $3.58(\mathrm{dd}, 1 \mathrm{H}, J=4,4$ and $9.2 \mathrm{~Hz}, \mathrm{H}-6 \mathrm{~b}), 3.34\left(\mathrm{~s}, 3 \mathrm{H},-\mathrm{OCH}_{3}\right), 2.43(\mathrm{~s}$, $3 \mathrm{H}$, tosyl $\left.\mathrm{CH}_{3}\right), 0.87\left(\mathrm{~s}, 9 \mathrm{H}\right.$, tert-butyl $\left.\mathrm{CH}_{3}\right), 0.06\left(\mathrm{~s}, 6 \mathrm{H},-\mathrm{Si}\left(\mathrm{CH}_{3}\right)_{2}\right) .{ }^{13} \mathrm{C} \mathrm{NMR}(100 \mathrm{MHz}$, $\mathrm{CDCl}_{3}$ ) / ppm: 145.0, 133.2, 129.7 (x2), 127.9 (x2), 100.2, 82.5, 71.4, 69.3, 66.6, 54.8, 25.7 (x9), 21.5, 18.1, -5.6. MALDI HRMS $m / z$ [M + Na] ${ }^{+}\left(\mathrm{C}_{20} \mathrm{H}_{34} \mathrm{O}_{8} \mathrm{SSiNa}\right)$, Calculated: 485.1641; Found: 485.1630 .

Methyl 3-O-(4-toluenesulfonyl)-6-O-tert-butyldiphenylsilyl- $\alpha$-D-mannopyranoside 14

Eluted from the column with hexane/ethyl acetate (from 3:1 to 1:2). Rf (hexane/ethyl acetate 3:2) $0.75 .{ }^{1} \mathrm{H}$ NMR $\left(400 \mathrm{MHz}, \mathrm{CDCl}_{3}\right) \delta / \mathrm{ppm}: 7.707 .35(\mathrm{~m}, 14 \mathrm{H}$, aromatic protons), $4.70(\mathrm{dd}, 1 \mathrm{H}, J=2.8$ and $9.2 \mathrm{~Hz}, \mathrm{H}-3), 4.68$ (bs, $1 \mathrm{H}, \mathrm{H}-1), 4.05-3.99(\mathrm{~m}, 2 \mathrm{H}, \mathrm{H}-2$ and $\mathrm{H}-4)$, $3.90\left(\mathrm{~d}, 2 \mathrm{H}, J=3.2 \mathrm{~Hz}, \mathrm{H}_{2}-6\right), 3.57(\mathrm{~m}, 1 \mathrm{H}, \mathrm{H}-5), 3.32\left(\mathrm{~s}, 3 \mathrm{H},-\mathrm{OCH}_{3}\right), 2.45$ (s, 3H, tosyl $\left.\mathrm{CH}_{3}\right), 1.04\left(\mathrm{~s}, 9 \mathrm{H}\right.$, tert-butyl $\left.\mathrm{CH}_{3}\right), 0.06\left(\mathrm{~s}, 6 \mathrm{H},-\mathrm{Si}\left(\mathrm{CH}_{3}\right)_{2}\right) .{ }^{13} \mathrm{C} \mathrm{NMR}\left(100 \mathrm{MHz}, \mathrm{CDCl}_{3}\right)$ ठ/ppm: 145.0, 135.5, 135.3, 133.2, 132.9, 129.7, 127.6, 100.2, 82.5, 71.6, 69.4, 66.2, 63.9, 54.8, 26.7 (x9), 21.6, 19.1. MALDI HRMS $m / z$ [M + Na $]^{+}\left(\mathrm{C}_{30} \mathrm{H}_{38} \mathrm{O}_{8} \mathrm{SSiNa}\right)$, Calculated: 609.1954; Found: 609.1965.

Allyl 3-O-(4-toluenesulfonyl)-6-O-tert-butyldimethylsilyl- $\beta$-D-galactopyranoside 15

Eluted from the column with hexane/ethyl acetate (3:2). Rf (hexane/ethyl acetate 3:2) 0.50. ${ }^{1} \mathrm{H}$ NMR $\left(400 \mathrm{MHz}, \mathrm{CDCl}_{3}\right) \delta / \mathrm{ppm}: 7.85$ and $7.30(2 \times \mathrm{d}, 4 \mathrm{H}, J=8.0 \mathrm{~Hz}$, aromatic protons), 5.87-5.82 (m, $\left.1 \mathrm{H},-\mathrm{CH}=\mathrm{CH}_{2}\right), 5.26$ (bd, $1 \mathrm{H}, J=17.2 \mathrm{~Hz},-\mathrm{CH}=\mathrm{CH}$ cis Htrans), 5.17 (bd, $1 \mathrm{H}, J=10.2 \mathrm{~Hz},-\mathrm{CH}=\mathrm{CH}$ cis Htrans), $4.45(\mathrm{dd}, 1 \mathrm{H}, J=2.8$ and $10.0 \mathrm{~Hz}, \mathrm{H}-3), 4.35-4.25$ $\left(\mathrm{m}, 2 \mathrm{H}, \mathrm{H}-1\right.$ and $\left.-\mathrm{CHaHbCH}=\mathrm{CH}_{2}\right), 4.15-4.00\left(\mathrm{~m}, 2 \mathrm{H}, \mathrm{H}-4\right.$ and $\left.-\mathrm{CHaHbCH}=\mathrm{CH}_{2}\right), 3.90-3.80$ $\left(\mathrm{m}, 3 \mathrm{H}, \mathrm{H}_{2}-6\right.$ and $\left.\mathrm{H}-2\right), 3.43(\mathrm{bt}, 1 \mathrm{H}, J=6.8 \mathrm{~Hz}, \mathrm{H}-5), 2.42\left(\mathrm{~s}, 3 \mathrm{H}\right.$, toluensulfonyl $\left.\mathrm{CH}_{3}\right), 0.86$ (s, 9H, tert-butyl $\left.\mathrm{CH}_{3}\right), 0.47\left(\mathrm{~s}, 6 \mathrm{H},-\mathrm{SiCH}_{3}\right) .{ }^{13} \mathrm{C} \mathrm{NMR}\left(100 \mathrm{MHz}, \mathrm{CDCl}_{3}\right) \delta / \mathrm{ppm}: 144.8$, 133.5, 129.6, 127.8, 117.9, 101.7, 82.9, 73.7, 70.0, 68.9, 67.8, 61.9, 25.7 (x9), 21.6, 18.1, -5.6. MALDI HRMS $m / z$ [M + Na] $]^{+}\left(\mathrm{C}_{22} \mathrm{H}_{36} \mathrm{O}_{8} \mathrm{SSiNa}\right)$, Calculated: 609.1954; Found: 511.1798.

Methyl 3-O-(4-toluenesulfonyl)-6-O-trityl- $\alpha$-D-mannopyranoside 16

Eluted from the column with hexane/ethyl acetate (1:1). Rf (hexane/ethyl acetate 1:1) 0.45. ${ }^{1} \mathrm{H} \mathrm{NMR}\left(400 \mathrm{MHz}, \mathrm{CDCl}_{3}\right.$ ) $\delta / \mathrm{ppm}$ : 7.70-7.20 (m, 19H, aromatic protons), 4.72 (bs, $1 \mathrm{H}$, $\mathrm{H}-1), 4.68(\mathrm{dd}, 1 \mathrm{H}, J=3.2$ and $9.2 \mathrm{~Hz}, \mathrm{H}-3), 4.01(\mathrm{bs}, 1 \mathrm{H}, \mathrm{H}-2), 3.96(\mathrm{t}, 1 \mathrm{H}, J=9.6 \mathrm{~Hz}, \mathrm{H}-4)$, 
$3.68(\mathrm{~m}, 1 \mathrm{H}, \mathrm{H}-5), 3.45-3.32\left(\mathrm{~m}, 2 \mathrm{H}, \mathrm{H}_{2}-6\right), 3.36\left(\mathrm{~s}, 3 \mathrm{H},-\mathrm{OCH}_{3}\right), 2.44\left(\mathrm{~s}, 3 \mathrm{H}\right.$, tosyl $\left.\mathrm{CH}_{3}\right), 2.35$ (bs, 1H, OH). $\left.{ }^{13} \mathrm{C} \mathrm{NMR} \mathrm{(100} \mathrm{MHz,} \mathrm{CDCl}_{3}\right) \delta / \mathrm{ppm}: 145.0,143.5,133.2,129.8-127.0,100.2$, 86.9, 82.4, 70.7, 69.4, 66.4, 63.8, 54.8, 21.6. MALDI HRMS $m / z[\mathrm{M}+\mathrm{Na}]^{+}\left(\mathrm{C}_{33} \mathrm{H}_{34} \mathrm{O}_{8} \mathrm{SNa}\right)$, Calculated: 613.1872; Found: 613.1881.

Methyl 3-O-(4-toluenesulfonyl)- $\beta$-L-fucopyranoside 17

Eluted from the column with hexane/ethyl acetate (from 2:3 to 0:1). Rf (hexane/ethyl acetate 2:3) 0.65. ${ }^{1} \mathrm{H}$ NMR $\left(400 \mathrm{MHz}, \mathrm{CDCl}_{3}\right) \delta / \mathrm{ppm}: 7.84$ and $7.33(2 \times \mathrm{d}, 4 \mathrm{H}, J=8.0 \mathrm{~Hz}$, aromatic protons), $4.46(\mathrm{dd}, 1 \mathrm{H}, J=3.2$ and $10.0 \mathrm{~Hz}, \mathrm{H}-3), 4.13(\mathrm{~d}, 1 \mathrm{H}, J=7.6 \mathrm{~Hz}, \mathrm{H}-1), 3.94$ (bd, 1H, J = 3.2 Hz, H-4), 3.76 (t, 1H, J = 7.6 Hz, H-2), 3.61 (q, 1H, J = 6.4 Hz, H-5), 3.51 (s, $\left.3 \mathrm{H},-\mathrm{OCH}_{3}\right), 2.44\left(\mathrm{~s}, 3 \mathrm{H}\right.$, tosyl $\left.\mathrm{CH}_{3}\right), 1.33\left(\mathrm{t}, 1 \mathrm{H}, J=6.4 \mathrm{~Hz}, \mathrm{H}_{3}-6\right) .{ }^{13} \mathrm{C} \mathrm{NMR}(100 \mathrm{MHz}$, $\mathrm{CDCl}_{3}$ ) $\delta$ /ppm: 145.0, 133.2, 129.7 (x2), 127.9 (x2), 103.5, 83.0, 70.0, 69.4, 68.8, 57.0, 21.6, 15.9. MALDI HRMS $m / z$ [M + Na $]^{+}\left(\mathrm{C}_{14} \mathrm{H}_{20} \mathrm{O}_{7} \mathrm{SNa}\right)$, Calculated: 355.0827; Found: 355.0815.

\section{2-O-(4-toluenesulfonyl) diethyl tartrate 18 [22]}

Eluted from the column with hexane/ethyl acetate (from 3:2 to 1:2). Rf (hexane/ethyl acetate 1:1) 0.66. ${ }^{1} \mathrm{H} \mathrm{NMR}\left(400 \mathrm{MHz}, \mathrm{CDCl}_{3}\right) \delta / \mathrm{ppm}: 7.79$ and $7.32(2 \times \mathrm{d}, 4 \mathrm{H}, J=8.0 \mathrm{~Hz}$, aromatic protons), 5.31 (bs, $1 \mathrm{H}, \mathrm{H}-2), 4.70(\mathrm{~d}, 1 \mathrm{H}, J=6.0 \mathrm{~Hz}, \mathrm{H}-3), 4.25-3.95(\mathrm{~m}, 4 \mathrm{H}, 2 \times$ $\left.-\mathrm{OCH}_{2} \mathrm{CH}_{3}\right), 3.20(\mathrm{~d}, 1 \mathrm{H}, \mathrm{J}=6.0 \mathrm{~Hz}, \mathrm{OH}-3), 2.42\left(\mathrm{~s}, 3 \mathrm{H}\right.$, toluensulfonyl $\left.\mathrm{CH}_{3}\right), 1.26$ and 1.22 $\left(2 \times \mathrm{t}, 6 \mathrm{H}, J=7.6 \mathrm{~Hz}, 2 \times-\mathrm{OCH}_{2} \mathrm{CH}_{3}\right) .{ }^{13} \mathrm{C} \mathrm{NMR}\left(100 \mathrm{MHz}, \mathrm{CDCl}_{3}\right) \delta / \mathrm{ppm}: 169.7,165.6$, $145.2,133.0,129.5,128.0,76.9,71.1,62.9,62.4,21.5,13.8(x 2)$. MALDI HRMS $m / z[\mathrm{M}+\mathrm{Na}]^{+}$ $\left(\mathrm{C}_{15} \mathrm{H}_{20} \mathrm{O}_{8} \mathrm{SNa}\right)$, Calculated: 383.0777; Found: 383.0768 .

Methyl 2-O-(4-toluenesulfonyl)-4,6-O-benzylidene- $\alpha$-D-glucopyranoside 19 [45]

Eluted from the column with hexane/ethyl acetate (from 1:1 to 1:2). Rf (hexane/ethyl acetate 1:1) 0.50. ${ }^{1} \mathrm{H} \mathrm{NMR}\left(400 \mathrm{MHz}, \mathrm{CDCl}_{3}\right) \delta / \mathrm{ppm}: 7.70-7.20$ (m, 9H, aromatic protons), $5.49(\mathrm{~s}, 1 \mathrm{H},-\mathrm{CHPh}), 4.84(\mathrm{~d}, 1 \mathrm{H}, \mathrm{J}=3.6 \mathrm{~Hz}, \mathrm{H}-1), 4.38(\mathrm{dd}, 1 \mathrm{H}, \mathrm{J}=3.6$ and $9.2 \mathrm{~Hz}, \mathrm{H}-2), 4.27$ $(\mathrm{dd}, 1 \mathrm{H}, J=4.4$ and $10.0 \mathrm{~Hz}, \mathrm{H}-6 \mathrm{eq}), 4.14(\mathrm{t}, 1 \mathrm{H}, J=9.2 \mathrm{~Hz}, \mathrm{H}-3), 3.81(\mathrm{~m}, 1 \mathrm{H}, \mathrm{H}-5), 3.71(\mathrm{t}$, $1 \mathrm{H}, J=10.0 \mathrm{~Hz}, \mathrm{H}-6 \mathrm{ax}), 3.46(\mathrm{dd}, 1 \mathrm{H}, J=9.2$ and $10.0 \mathrm{~Hz}, \mathrm{H}-4), 3.35$ (s, 3H, $\left.-\mathrm{OCH}_{3}\right), 2.44$ (s,

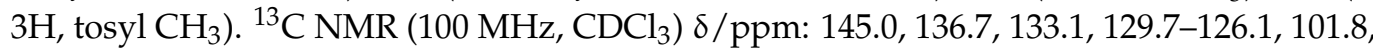
98.0, 80.8, 79.4, 68.6, 68.2, 61.8, 55.6, 21.6. MALDI HRMS $m / z[\mathrm{M}+\mathrm{Na}]^{+}\left(\mathrm{C}_{21} \mathrm{H}_{24} \mathrm{O}_{8} \mathrm{SNa}\right)$, Calculated: 459.1090; Found: 459.1098.

Methyl 3-O-(4-toluenesulfonyl)-4,6-O-benzylidene- $\alpha$-D-mannopyranoside 20 [27]

Eluted from the column with hexane/ethyl acetate (from 3:2 to 1:2). Rf (hexane/ethyl acetate 1:1) 0.65. ${ }^{1} \mathrm{H} \mathrm{NMR}\left(400 \mathrm{MHz} \mathrm{CDCl}_{3}\right) \delta / \mathrm{ppm}$ : 7.85-7.00 (m, 9H, aromatic protons), 5.39 (s, 1H, -CHPh), 4.77 (dd, 1H, $J=3.2$ and $9.6 \mathrm{~Hz}, \mathrm{H}-3), 4.75$ (bs, 1H, H-1), 4.32 (bs, $1 \mathrm{H}, \mathrm{H}-2), 4.21$ (m, 1H, H-6eq), 4.08 (t, 1H, $J=9.6 \mathrm{~Hz}, \mathrm{H}-4), 3.80-3.70$ (m, 2H, H-5 and H-6ax), 3.38 (s, 3H, $\left.-\mathrm{OCH}_{3}\right), 2.31$ (s, 3H, tosyl $\left.\mathrm{CH}_{3}\right) .{ }^{13} \mathrm{C} \mathrm{NMR}\left(100 \mathrm{MHz}, \mathrm{CDCl}_{3}\right) \delta / \mathrm{ppm}$ : $144.5,136.8,129.4-126.1,101.6,101.4,78.6,75.3,70.4,68.5,63.6,55.0,21.5$. MALDI HRMS $m / z[\mathrm{M}+\mathrm{Na}]^{+}\left(\mathrm{C}_{21} \mathrm{H}_{24} \mathrm{O}_{8} \mathrm{SNa}\right)$, Calculated: 459.1090; Found: 459.1083.

\section{Conclusions}

In conclusion, in this paper we have demonstrated that the application of solventfree conditions can offer a simple opportunity to carry out the regioselective tosylation of saccharide building-blocks at secondary positions, favoring the functionalization of equatorial hydroxy groups cis-oriented towards a vicinal hydroxy group. Besides the experimental simplicity, the methodology appears especially convenient because of the reduced experimental times needed. In addition, the method is based on cheap and commercially available reagents, and provides synthetically useful yields with a broad range of substrates, including polyols bearing unprotected primary alcohols.

Supplementary Materials: The following are available online at https: / /www.mdpi.com/2073-434 4/11/2/202/s1, Pages S1-S10 copies of ${ }^{1} \mathrm{H}$ and ${ }^{13} \mathrm{C}$ NMR spectra of all synthesized products.

Author Contributions: Conceptualization, A.I., S.T.; methodology, A.I., S.T.; synthetic experiments, all authors; discussion of experimental results, all authors; writing-original draft preparation, A.I., S.T.; writing-review and editing, all authors. All authors have read and agreed to the published version of the manuscript. 
Funding: This research was funded by MIUR (Ministero dell'Istruzione, dell'Università e della Ricerca, Rome, Italy), FFABR-2017 grant.

Data Availability Statement: Not applicable.

Conflicts of Interest: The authors declare no conflict of interest.

\section{References}

1. Boons, G.-J.; Hale, K.J. Organic Synthesis with Carbohydrates; Sheffield Academic Press: Sheffield, UK, 2000.

2. Hughes, N.A.; Speakman, P.R.H. Benzoate displacements on 3-O-toluene- $p$-sulphonyl-D-glucose derivatives; a new synthesis of D-allose. J. Chem. Soc. 1965, 2236-2239. [CrossRef]

3. Ahluwahlia, R.; Angyal, S.J.; Randall, M.H. Synthesis of the methyl D-allopyranosides and of D-allose from 1,2:5,6-di-Oisopropylidene-3-O-p-tolylsulfonyl- $\alpha$-D-glucofuranose. Carbohydr. Res. 1967, 4, 478-485. [CrossRef]

4. Siewert, G.; Westphal, O. Substitution of secondary tosyl ester groups by iodine. Synthesis of 4-deoxy-and 4,6-dideoxy-D-xylohexose. Justus Liebigs Ann. Chem. 1969, 720, 161-170. [CrossRef]

5. Koto, S.; Kawakatsu, N.; Zen, S. Synthesis of 3-amino-3-deoxy-D-allose and related substances. Bull. Chem. Soc. Jpn. 1973, 46, 876-880. [CrossRef]

6. Ogawa, S.; Iwasawa, Y.; Toyokuni, T.; Suami, T. Synthesis of pseudooligosaccharidic glycosidase inhibitors. Part 1. Synthesis of adiposin-1 and related compounds. Carbohydr. Res. 1985, 141, 29-40. [CrossRef]

7. Kong, F.; Su, B. Formation of 2,3-unsaturated pyranoid derivatives from a D-mannopyranose p-toluenesulfonate. Carbohydr. Res. 1985, 142, 152-157. [CrossRef]

8. Molino, B.F.; Fraser-Reid, B. Pyranosidic homologation. VII. Controlled formation of dipyranoside derivatives through carbon 6 and oxygen 4. Can. J. Chem. 1987, 65, 2834-2842. [CrossRef]

9. Czernecki, S.; Valery, J.M. A convenient synthesis of methyl 2,3-di-O-benzyl-4-deoxy- $\alpha$-D-xylo-hexodialdo-1,5-pyranoside and its stereospecific ethynylation. J. Carbohydr. Chem. 1989, 8, 793-798. [CrossRef]

10. Varela, O.; Cicero, D.; De Lederkremer, R.M. A convenient synthesis of 4-thio-D-galactofuranose. J. Org. Chem. 1989, 54, 1884-1890. [CrossRef]

11. Capek, K.; Cadova, E.; Sedmera, P. 2,3'-Anhydrosucrose. Carbohydr. Res. 1990, 205, 161-171.

12. Tsuda, Y.; Nishimura, M.; Ito, Y. Utilization of sugars in organic synthesis 23. Lithium alluminium hydride reduction of glycopyranoside monosulfonates. Formation of branched furanosides. Chem. Pharm. Bull. 1991, 39, 1983-1989. [CrossRef]

13. Wu, X.; Kong, F.; Lu, D.; Li, G. Synthesis, crystalline structure, conformational analysis, and azidolysis of methyl 2,3-anhydro- $\alpha$ D-manno- and -allo-pyranoside $p$-bromobenzyl ethers. Carbohydr. Res. 1992, 235, 163-178. [CrossRef]

14. Kawana, M.; Tsujimoto, M.; Takahashi, S. One-pot $p$-toluenesulfonylation of adenosine and methyl glycosides with a substoichiometric amount of organotin mediators. J. Carbohydr. Chem. 2000, 19, 67-78. [CrossRef]

15. Deshpande, S.G.; Pathak, T. Synthesis and synthetic applications of 1-(3-O-tosyl- $\beta$-D-glucopyranosyl)-thymines: Toward new classes of hexopyranosyl pyrimidines. Tetrahedron Lett. 2004, 45, 2255-2258. [CrossRef]

16. Deshpande, S.G.; Pathak, T. A general and efficient route to $3^{\prime}$-deoxy-3'-N-, S-, and C-substituted altropyranosyl thymines from 2',3'-O-anhydro-mannopyranosylthymine. Tetrahedron 2007, 63, 602-608. [CrossRef]

17. Khan, K.M.; Perveen, S.; Al-Qawasmeh, R.A.S.; Shekhani, M.S.; Shah, S.T.A.; Voelter, W. A method for the syntheses of eno-pyranosides. Lett. Org. Chem. 2009, 6, 191-196. [CrossRef]

18. Xia, L.; Lowary, T.L. Regioselective polymethylation of $\alpha-(1 \rightarrow 4)$-linked mannopyranose oligosaccharides. J. Org. Chem. 2013, 78, 2863-2880. [CrossRef]

19. Hevey, R.; Chen, X.; Ling, C.-C. Role of the 4,6-O-acetal in the regio- and stereoselective conversion of 2,3-di-O-sulfonyl- $\beta$-Dgalactopyranosides to D-idopyranosides. Carbohydr. Res. 2013, 376, 37-48. [CrossRef]

20. Tsuda, Y.; Nishimura, M.; Kobayashi, T.; Sato, Y.; Kanemitsu, K. Utilization of sugars in organic synthesis. XXIV. Regioselective monotosylation of non-protected and partially protected glycosides by the dibutyltin oxide method. Chem. Pharm. Bull. 1991, 39, 2883-2887. [CrossRef]

21. Martinelli, M.J.; Nayyar, N.K.; Moher, E.D.; Dhokte, U.P.; Pawlak, J.M.; Vaidyanathan, R. Dibutyltin oxide catalyzed selective sulfonylation of $\alpha$-chelatable primary alcohols. Org. Lett. 1999, 1, 447-450. [CrossRef]

22. Martinelli, M.J.; Vaidyanathan, R.; Pawlak, J.M.; Nayyar, N.K.; Dhokte, U.P.; Doecke, C.W.; Zollars, L.M.H.; Moher, E.D.; Van Khau, V.; Kosmrlj, B. Catalytic Regioselective Sulfonylation of a-Chelatable Alcohols: Scope and Mechanistic Insight. J. Am. Chem. Soc. 2002, 124, 3578-3585. [CrossRef] [PubMed]

23. Donthulachitti, C.; Kothakapu, S.R.; Shekunti, R.K.; Neella, C.K. [DMAPTs] ${ }^{+} \mathrm{Cl}^{-}$: A Promising Versatile Regioselective Tosyl Transfer Reagent. ChemistrySelect 2017, 2, 5321-5328. [CrossRef]

24. Muramatsu, W. Chemo- and Regioselective Monosulfonylation of Nonprotected Carbohydrates Catalyzed by Organotin Dichloride under Mild Conditions. J. Org. Chem. 2012, 77, 8083-8091. [CrossRef] [PubMed]

25. Lee, D.; Williamson, C.L.; Chan, L.; Taylor, M.S. Regioselective, Borinic Acid-Catalyzed Monoacylation, Sulfonylation and Alkylation of Diols and Carbohydrates: Expansion of Substrate Scope and Mechanistic Studies. J. Am. Chem. Soc. 2012, 134, 8260-8267. [CrossRef] 
26. Kuwano, S.; Hosaka, Y.; Ara, T. Chiral Benzazaborole-Catalyzed Regioselective Sulfonylation of Unprotected Carbohydrate Derivatives. Chem. Eur. J. 2019, 25, 12920-12923. [CrossRef]

27. Kusano, S.; Miyamoto, S.; Matsuoka, A.; Yamada, Y.; Ishikawa, R.; Hayashida, O. Benzoxaborole Catalyst for Site-Selective Modification of Polyols. Eur. J. Org. Chem. 2020, 1598-1602. [CrossRef]

28. Lv, J.; Zhu, J.-J.; Liu, Y.; Dong, H. Regioselective Sulfonylation/Acylation of Carbohydrates Catalyzed by $\mathrm{FeCl}_{3} \mathrm{Combined} \mathrm{with}$ Benzoyltrifluoroacetone and Its Mechanism Study. J. Org. Chem. 2020, 85, 3307-3319. [CrossRef]

29. Traboni, S.; Bedini, E.; Vessella, G.; Iadonisi, A. Solvent-Free Approaches in Carbohydrate Synthetic Chemistry: Role of Catalysis in Reactivity and Selectivity. Catalysts 2020, 10, 1142. [CrossRef]

30. Giordano, M.; Iadonisi, A. A practical approach to regioselective O-benzylation of primary positions of polyols. Tetrahedron Lett. 2013, 54, 1550-1552. [CrossRef]

31. Giordano, M.; Iadonisi, A. Tin-mediated regioselective benzylation and allylation of polyols: Applicability of a catalytic approach under solvent-free conditions. J. Org. Chem. 2014, 79, 213-222. [CrossRef]

32. Sethi, K.P.; Kartha, K.P.R. Stannylene acetal-mediated solvent-free mechanochemical regioselective alkylation of galactosides and lactosides. Trends Carbohydr. Res. 2016, 8, 29-32.

33. Gathirwa, J.W.; Maki, T. Benzylation of hydroxy groups with tertiary amine as a base. Tetrahedron 2012, 68, 370-375. [CrossRef]

34. Traboni, S.; Bedini, E.; Iadonisi, A. Orthogonal protection of saccharide polyols through solvent-free one-pot sequences based on regioselective silylations. Beilstein J. Org. Chem. 2016, 12, 2748-2756. [CrossRef]

35. Patil, P.R.; Karth, K.P.R. Application of ball billing technology to carbohydrate reactions: I. Regioselective primary hydroxyl protection of hexosides and nucleoside by planetary ball milling. J. Carbohydr. Chem. 2008, 27, 279-293. [CrossRef]

36. Traboni, S.; Bedini, E.; Iadonisi, A. Solvent-free one-pot diversified protection of saccharide polyols via regioselective tritylation. ChemistrySelect 2017, 2, 4906-4911. [CrossRef]

37. Traboni, S.; Bedini, E.; Giordano, M.; Iadonisi, A. Three solvent-free catalytic approaches to the acetal functionalization of carbohydrates and their applicability to one-pot generation of orthogonally protected building blocks. Adv. Synth. Catal. 2015, 357, 3562-3572. [CrossRef]

38. Traboni, S.; Bedini, E.; Giordano, M.; Iadonisi, A. One-pot synthesis of orthogonally protected sugars through sequential basepromoted/acid-catalyzed steps: A solvent-free approach with self-generation of a catalytic species. Tetrahedron Lett. 2019, 60, 1777-1780. [CrossRef]

39. Traboni, S.; Vessella, G.; Bedini, E.; Iadonisi, A. Solvent-free, under air selective synthesis of a-glycosides adopting glycosyl chlorides as donors. Org. Biomol. Chem. 2020, 18, 5157-5163. [CrossRef]

40. Patil, P.R.; Kartha, K.P.R. Solvent-free synthesis of thioglycosides by ball milling. Green Chem. 2009, 11, 953-956. [CrossRef]

41. Kumar, V.; Yadav, N.; Kartha, K.P.R. In(III) triflate-catalyzed detritylation and glycosylation by solvent-free ball milling. Carbohydr. Res. 2014, 397, 18-26. [CrossRef]

42. Kumar, V.; Taxak, N.; Jangir, R.; Bharatam, P.V.; Kartha, K.P.R. In(III) triflate-mediated solvent-free synthesis and activation of thioglycosides by ball milling and structural analysis of long chain alkyl thioglycosides by TEM and quantum chemical methods. J. Org. Chem. 2014, 79, 3427-3439. [CrossRef] [PubMed]

43. Traboni, S.; Liccardo, F.; Bedini, E.; Giordano, M.; Iadonisi, A. Solvent-free synthesis of glycosyl chlorides based on the triphenyl phosphine/hexachloroacetone system. Tetrahedron Lett. 2017, 58, 1762-1764. [CrossRef]

44. Traboni, S.; Bedini, E.; Iadonisi, A. Solvent-free conversion of alcohols to alkyl iodides and one-pot elaborations thereof. ChemistrySelect 2018, 3, 1616-1622. [CrossRef]

45. Bauder, C. A convenient synthesis of orthogonally protected 2-deoxystreptamine (2-DOS) as an aminocyclitol scaffold for the development of novel aminoglycoside antibiotic derivatives against bacterial resistance. Org. Biomol. Chem. 2008, 6, 2952-2960. [CrossRef]

46. Xu, H.; Zhang, Y.; Dong, H.; Lu, Y.; Pei, Y.; Pei, Z. Organotin-catalyzed regioselective benzylation of carbohydrate trans-diols. Tetrahedron Lett. 2017, 58, 4039-4042. [CrossRef] 